\title{
Noradrenaline Hyperpolarizes Identified Rat Mesopontine Cholinergic Neurons in vitro
}

\author{
Julie A. Williams and Peter B. Reiner \\ Kinsmen Laboratory of Neurological Research, Department of Psychiatry, University of British Columbia, Vancouver, \\ British Columbia V6T 173, Canada
}

\begin{abstract}
Inhibition of brainstem cholinergic neurons by noradrenergic neurons of the locus ceruleus has long been suggested as a key mechanism of behavioral state control. In particular, the commonly held view is that noradrenaline (NA) plays a permissive role in rapid eye movement (REM) sleep generation by disinhibiting brainstem cholinergic neurons. While this notion has been supported by numerous investigations, the inhibition of cholinergic neurons by NA has never been directly demonstrated. The purpose of this study was to investigate the effects of NA upon identified cholinergic neurons in the rat mesopontine tegmentum.

Using whole-cell patch-clamp recordings in slices, 175 cells were studied during bath application of $50 \mu \mathrm{M}$ NA. Cholinergic neurons were positively identified by intracellular labeling with blocytin and subsequent staining with NADPHdiaphorase, a reliable marker for brainstem cholinergic neurons (Vincent et al., 1983). Successful intracellular labeling was obtained in 96 cells. Ninety-two percent (36 of 39) of cholinergic neurons hyperpolarized in response to NA, while noncholinergic cells $(n=57)$ exhibited mixed responses. Application of $\mathrm{NA}$ in a low-Ca ${ }^{2+}$, high-Mg ${ }^{2+}$ solution elicited the same hyperpolarizing effect as in normal solution, which indicated that the effect of NA on cholinergic neurons was direct. The noradrenergic hyperpolarization was mimicked by the $\alpha_{2}$-adrenoceptor agonist UK-14,304, and was blocked by the $\alpha 2$-adrenoceptor antagonist idazoxan, which suggested an $\alpha 2$-mediated response. Finally, voltage-clamp experiments revealed that NA activates the inwardly rectifying potassium current, $I_{\text {kG. }}$.
\end{abstract}

These data unambiguously confirm the hypothesis that NA inhibits brainstem cholinergic neurons, and are fundamental to understanding the role of noradrenergic-cholinergic interactions in behavioral state control.

IKey words: REM sleep, locus ceruleus, a2-adrenergic receptors, potassium currents, NADPH-diaphorase, behavioral state control]

The most widely accepted model of rapid eye movement (REM) sleep generation is that release of $\mathrm{ACh}$ within the medial pontine reticular formation (MPRF) is one, if not the, natural trigger for

Received Nov. 5, 1992; revised Feb. 17, 1993; accepted Mar. 18, 1993.

We thank Andy Laycock for technical assistance. This work was supported by grants from the British Columbia Health Care Research Foundation and MRC. J.A.W. received partial support from the IODE. P.B.R. is an MRC Scholar.

Correspondence should be addressed to Peter B. Reiner, Kinsmen Laboratory of Neurological Research, Department of Psychiatry, University of British Columbia, 2255 Wesbrook Mall, Vancouver, BC V6T 1 Z3 Canada.

Copyright (C) 1993 Society for Neuroscience $0270-6474 / 93 / 133878-06 \$ 05.00 / 0$
REM sleep generation. This is based upon the well-established observation that microinjection of cholinergic agonists into the MPRF induces a state indistinguishable from REM sleep (Baxter, 1969; Mitler and Dement, 1974; Amatruda et al., 1975). That amines inhibit this cholinergic trigger was suggested by the observation that systemic administration of the anti-AChE agent eserine induces a state indistinguishable from REM sleep, but only after depletion of amines by reserpine (Karczmar et al., 1970). Based upon extracellular recordings of (1) neurons selectively active during REM sleep in the gigantocellular tegmental field (FTG) where AChE-positive neurons are found, and (2) neurons that fall silent during REM sleep in the noradrenergic locus ceruleus (LC) (Hobson et al., 1975) and serotonergic dorsal raphe (DR) nuclei (McGinty and Harper, 1972), McCarley and Hobson (1975) proposed the reciprocal-interaction hypothesis: that the sleep cycle is controlled by an inhibitory aminergic population and a reciprocally cxcitatory cholinergic population, in which the silence of aminergic neurons would disinhibit cholinergic neurons and thereby evoke REM sleep by release of ACh in the MPRF.

The striking behavioral neurophysiological profile of noradrenergic and serotonergic neurons has been fully confirmed in numerous studies (McGinty and Harper, 1976; Trulson and Jacobs, 1979; Aston-Jones and Bloom, 1981; Reiner, 1985). However, two features of the original reciprocal-interaction model were subsequently shown to be invalid. First, the REM selectivity of FTG neuronal activity was found to be an artifact of head restraint (Siegel and McGinty, 1977; Vertes, 1977). Second, the AChE-positive neurons of the FTG were found not to be cholinergic when studied with ChAT immunohistochemistry (Jones and Beaudet, 1987; Vincent and Reiner, 1987; Shiromani et al., 1988). However, these same studies unambiguously demonstrated that the ncurons of the laterodorsal (LDT) and pedunculopontine (PPT) tegmental nuclei represent the predominant group of brainstem cholinergic neurons, and these neurons give rise to a massive innervation of the thalamus (Sofroniew et al., 1985; Satoh and Fibiger, 1986; Woolf and Butcher, 1986; Hallanger and Wainer, 1988; Steriade et al., 1988), as well as direct projections to the MPRF (Mitani et al., 1988; Shiromani et al., 1988; Quattrochi et al., 1989; Jones, 1990; Semba et al., 1990). Unfortunately, the behavioral neurophysiology of mesopontine cholinergic neurons is still not known with certainty. A small percentage of neurons in this region exhibit REM-selective discharge patterns, but the majority do not (El Mansari et al., 1989; Steriade et al., 1990). Based upon these data, Steriade et al. (1990) have concluded that cholinergic neurons are active during both wake and REM sleep, while other authors have argued otherwise (Sakai, 1988; Kamondi et al., 
1992). Barring more direct evidence, the behavior of mesopontine cholinergic neurons across states cannot be stated with complete confidence. Nonetheless, both the LDT and PPT contain neurons that are at least active during REM, and are thus candidates for being the cholinergic neurons that trigger the state of REM sleep.

Given these observations, the original reciprocal-interaction hypothesis has been considerably modified by various groups (Hobson et al., 1986; Sakai, 1988; Steriade and McCarley, 1990). One explicit prediction of all these models is that noradrenaline (NA) and 5-HT inhibit mesopontine cholinergic neurons. We have recently shown that 5 -HT inhibits identified cholinergic neurons (Luebke et al., 1992). Utilizing whole-cell patch-clamp recordings of LDT neurons in rat brain slices, we have now directly tested the other arm of this hypothesis, that NA hyperpolarizes mesopontine cholinergic neurons.

\section{Materials and Methods}

Methods for whole-cell recording, intracellular labeling, and histochemical identification of LDT cholinergic neurons in rat brain slices were similar to those of Kamondi et al. (1992). Briefly, rats 7-15 d old were anesthetized with halothane and decapitated, and the brains were rapidly removed and immersed in cold artificial cerebrospinal fluid (ACSF). The brain was trimmed to a block containing the pontomesencephalic tegmentum and cut into $400 \mu \mathrm{m}$ coronal sections with a Vibratome. Usually, two slices containing the LDT were obtained from each brain. Slices were stored in a holding chamber for at least $1 \mathrm{hr}$ before being transferred to a recording chamber where they were superfused with ACSF at $2 \mathrm{ml} / \mathrm{min}$. ACSF contained (in $\mathrm{mm}$ ) $126 \mathrm{NaCl}, 25 \mathrm{NaHCO}_{3}$, $1.2 \mathrm{NaH}_{2} \mathrm{PO}_{4}, 2.5 \mathrm{KCl}, 2.5 \mathrm{CaCl}_{2}, 1.2 \mathrm{MgCl}_{2}$, and 11 glucose, pH 7.4, when saturated with $95 \% \mathrm{O}_{2}, 5 \% \mathrm{CO}_{2}$. All experiments were carried out at room temperature.

Drugs were applied by superfusing the slice in ACSF containing a given concentration of the drug. Except for idazoxan and barium, drugs were stored in frozen aliquots at high concentrations and were thawed and diluted in ACSF prior to the experiment. NA, phenylephrine, and isoproterenol were obtained from Sigma Chemical Co.; idazoxan and UK-14,304, from Research Biochemicals, Inc.; and clonidine, from Boehringer Ingelheim, Ltd.

Patch pipettes were constructed from thin-wall $(1.5 \mathrm{~mm}$ o.d., $1.1 \mathrm{~mm}$ i.d.) borosilicate glass (Sutter Inst. Co.). The electrode solution contained (in mM) $15 \mathrm{NaCl}, 10 \mathrm{Na}$-HEPES, 11 EGTA, $140 \mathrm{KOH}, 1 \mathrm{CaCl}_{2}, 2 \mathrm{Mg}$ ATP, $0.3 \mathrm{GTP}$, and $0.2 \%$ biocytin, and was pH balanced with methanesulfonic acid to 7.4. Electrode resistance ranged from 4 to $6 \mathrm{M} \Omega$ in the recording chamber, typical electrode seals were 9-12 G $\Omega$, and access resistance following establishment of the whole-cell recording configuration ranged from 10 to $80 \mathrm{M} \Omega$. Both bridge mode and continuous single-electrode voltage-clamp recordings were obtained with an Axoclamp-2A. For voltage-clamp experiments, gains were from 5 to $10 \mathrm{nA} /$ $\mathrm{mV}$, and the output filter reduced from 30 to $1 \mathrm{kHz}$; neither capacitance nor series resistance compensation was utilized, as described elsewhere (Kamondi et al., 1992). Data were collected through an Axolab interface using pCLAMP computer software, version 5.0 (Axon Instruments), and recorded onto videotape in a digitized format. Data are reported as the mean $\pm \mathrm{SD}$.

Histochemical identification of recorded neurons. In order to identify biocytin-filled neurons unambiguously, only one cell was obtained from each side of a slice. Slices were nicked on one side during preparation to differentiate one side from the other. After experiments were complete, each slice was fixed overnight in $2 \%$ paraformaldehyde and $15 \%$ picric acid in $0.1 \mathrm{M}$ phosphatc-buffered saline (PBS), $\mathrm{pH}$ 7.4. The following day, slices were removed from the fixative and rinsed three times for $20 \mathrm{~min}$ in $0.1 \mathrm{M}$ PBS. Slices were then incubated in PBS containing $20 \mu \mathrm{g} / \mathrm{ml}$ Texas red-conjugated avidin and $0.3 \%$ Triton- $X$ for $2 \mathrm{hr}$, rinsed in PBS as before, and left in a Triton/PBS solution with $15 \%$ sucrose overnight. The next day slices were cut into $40-50 \mu \mathrm{m}$ sections with a cryostat and mounted onto coated slides.

Cholinergic neurons were identified using NADPH-diaphorase histochemistry, a reliable marker of LDT cholinergic neurons (Vincent et al., 1983). Slides were immersed in a solution containing $1 \mathrm{mg} / \mathrm{ml}$ NADPH and $0.1 \mathrm{mg} / \mathrm{ml}$ nitroblue tetrazolium in PBS and incubated at $37^{\circ} \mathrm{C}$ for $45-60 \mathrm{~min}$. Afterward, slices were rinsed in PBS and stored in the dark to dry. Slides were coverslipped and examined under a microscope equipped with both bright-field optics and epifluorescence for identification of NADPH-positive and Texas red-positive neurons, respectively.

\section{Results}

Identification of cholinergic and noncholinergic neurons This study is based upon whole-cell patch-clamp recordings of 175 cells in the LDT. Successful intracellular labeling with biocytin was obtained in 96 cells, and these were all processed for NADPH-diaphorase histochemistry. Forty-one percent (39 of 96) of biocytin-labeled cells were NADPH-diaphorase positive and thus identified as cholinergic. The remaining cells (57 of 96 , or $59 \%$ ) were noncholinergic (Fig. 1). The focus of the results reported below is largely upon the identified cholinergic neurons $(n=39)$.

The salient biophysical properties of the cholinergic neurons of the LDT were identical to those reported previously (Kamondi et al., 1992; Luebke et al., 1992). In brief, the majority of cholinergic neurons exhibited both the transient outward $\mathrm{K}^{+}$ current $I_{\mathrm{A}}$ and the transient inward $\mathrm{Ca}^{2+}$ current $I_{\mathrm{T}}$. In bridge mode these could be observed on the offset of hyperpolarizing current pulses: there was a delayed return to the resting potential $\left(I_{\mathrm{A}}\right)$ followed by a depolarizing overshoot $\left(I_{\mathrm{T}}\right)$ that often evoked a burst of action potentials.

\section{NA hyperpolarizes LDT cholinergic neurons}

Ninety-two percent (36 of 39) of identified cholinergic neurons hyperpolarized by $10.1 \pm 4.1 \mathrm{mV}$ in response to $50 \mu \mathrm{M}$ NA. In contrast, noncholinergic neurons exhibited heterogeneous responses to NA [ $35 \%$ (20 of 57) hyperpolarized, $46 \%$ (26 of 57 ) depolarized, 19\% (11 of 57) no response]. The hyperpolarization of cholinergic neurons was characterized by an increase in conductance, as illustrated in Figure $2, A$ and $B$. When the cell hyperpolarized by NA was returned to the resting potential by injection of depolarizing current, the input resistance was decreased as evidenced by smaller voltage deflections during the hyperpolarizing pulses as compared to control. Thus, NA hyperpolarizes cholinergic neurons by increasing an ionic conductance.

We next carried out experiments to determine if the noradrenergic effect was direct. To test this, two paradigms were utilized. First, in the majority of cases ( $n=27), 300 \mathrm{nM}$ TTX was included in the bath solution to block voltage-dependent sodium channels. The noradrenergic hyperpolarization always persisted under such conditions. Second, some slices $(n=4)$ were bathed in ACSF with low $\mathrm{Ca}^{2+}$ and high $\mathrm{Mg}^{2+}$ concentration $(0.5 \mathrm{~mm}$ and $10 \mathrm{mM}$, respectively) in addition to TTX to abolish $\mathrm{Ca}^{2+}$ dependent synaptic transmission. As shown in Figure $2 B$, the low- $\mathrm{Ca}^{2+}$ ACSF abolished the low-threshold $\mathrm{Ca}^{2+}$ spike normally seen after a $500 \mathrm{msec}$ hyperpolarizing pulse, thus ensuring a minimal synaptic $\mathrm{Ca}^{2+}$ influx and thereby synaptic transmission. Responses to NA in low $\mathrm{Ca}^{2+}$ were identical to those seen in the normal solution, which indicates that the noradrenergic effect is indeed direct (compare Fig. $2 A, C$ ).

\section{Noradrenergic hyperpolarization is mediated by $\alpha 2$-receptors}

Application of $1 \mu \mathrm{M}$ idazoxan, an $\alpha 2$-adrenergic antagonist, completely blocked the hyperpolarizing effect of NA on five of eight cholinergic cells and reduced the hyperpolarization in the other three cells by $2.3 \pm 0.5 \mathrm{mV}$. Interestingly, in three of the 

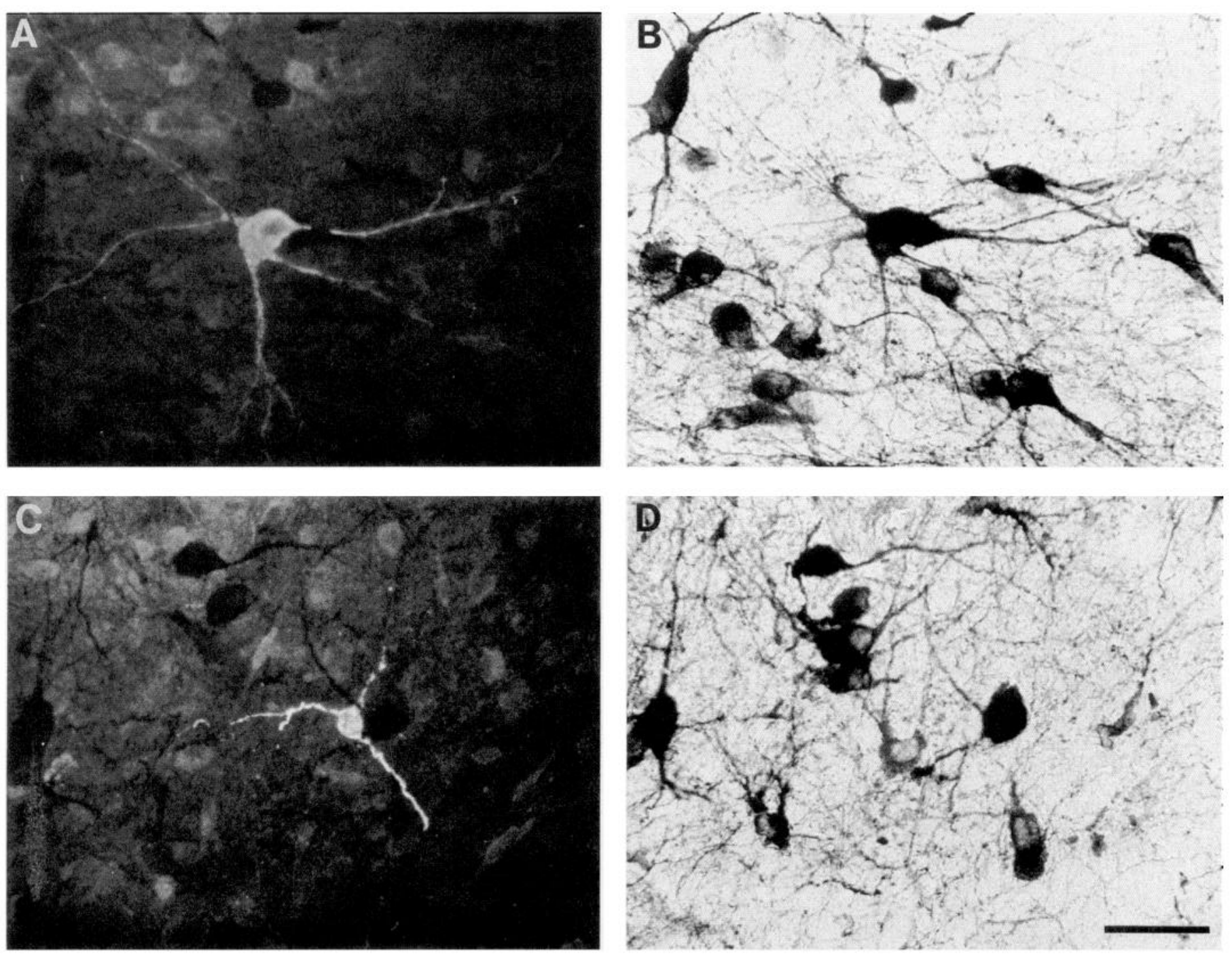

Figure 1. Histochemical identification of LDT nuclei. $A$ and $C$, Biocytin-filled neurons. $B$, NADPH-diaphorase histochemistry shows that the labeled neuron in $A$ is NADPH positive and therefore cholinergic. $D$, The labeled cell in $C$ did not stain for NADPH and is therefore noncholinergic. Scale bar, $25 \mu$ for $A-D$.

five cells in which the hyperpolarization was abolished by idazoxan, NA induced a depolarization of $5.0 \pm 1.6 \mathrm{mV}$ when $\alpha 2$-receptors were blocked (Fig. $2 D$ ). Thus, NA may have an additional effect on cholinergic neurons mediated by receptors other than the $\alpha 2$-receptor. However, these experiments were not carried out in low- $\mathrm{Ca}^{2+} \mathrm{ACSF}$, and therefore we do not know if the depolarization is a direct effect of NA. Both the $\alpha_{1-}$ agonist phenylephrine (10 $\mu \mathrm{M}, n=2)$ and the $\beta$-agonist isoproterenol ( $5 \mu \mathrm{M}, n=1)$ elicited no response from cells that exhibited a large hyperpolarization to NA. UK-14,304, a full $\alpha 2$-adrenoceptor agonist (Cambridge, 1981), induced a hyperpolarization of $5.8 \pm 2.3 \mathrm{mV}$ on cholinergic neurons $(10 \mu \mathrm{M}, n$ $=3$ ). Clonidine, a partial $\alpha 2$-adrenoceptor agonist (Medgett et al., 1978), had no effect on cholinergic neurons that were hyperpolarized by NA $(1-10 \mu \mathrm{M}, n=6)$. Because clonidine has also been reported to act as a competitive $\alpha 2$-antagonist, we tested its ability to block the noradrenergic hyperpolarization. It did not $(n=3)$. We therefore concluded that NA exerts its hyperpolarizing effect through an $\alpha 2$-adrenoceptor.

\section{NA activates $I_{K G}$}

As described above, the bridge mode data indicated an increase in conductance during the noradrenergic hyperpolarization of cholinergic neurons. Based upon the calculated equilibrium potentials of each of the ions in solution, we hypothesized that the increase in conductance was due to the activation of an outward potassium current. We tested this hypothesis by obtaining current-voltage $(I-V)$ ramps before and during application of NA $(n=5)$. As shown in Figure $3 A$, the ramps crossed at a position that approximated the calculated potassium equilibrium potential of $-101.5 \mathrm{mV}$. When the control $I-V$ ramps were subtracted from ones obtained during NA, the resulting curves showed inward rectification (Fig. $3 B$ ). This phenomenon is characteristic of the $\mathrm{K}^{+}$current directly activated by G-proteins, $I_{\mathrm{KG}}$ (Hille, 1992). Addition of $100 \mu \mathrm{M} \mathrm{Ba}{ }^{2+}$ (a nonspecific $\mathrm{K}^{+}$channel blocker) to the bath markedly reduced the current in three of three cells, as illustrated in Figure $3 C$, consistent with the hypothesis that NA is activating a $\mathrm{K}^{+}$current. We conclude that the nor- 
A

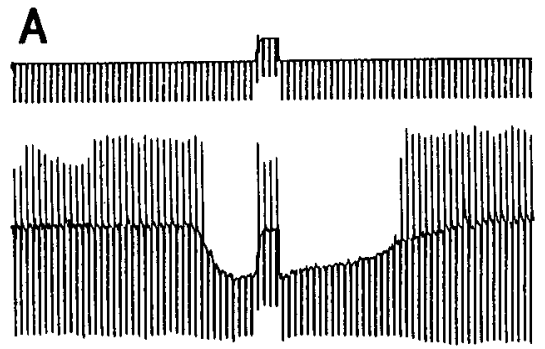

NA $50 \mu \mathrm{M}$

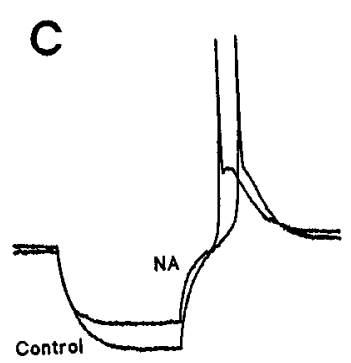

Low Calcium

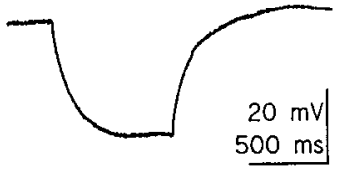

$500 \mathrm{~ms}$

B
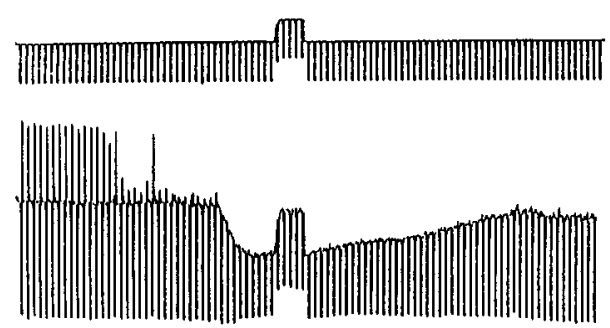

NA $50 \mu \mathrm{M}$

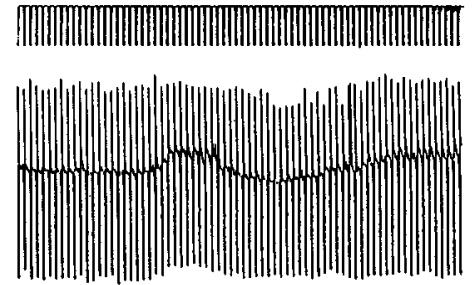

NA $50 \mu \mathrm{M}$
$20 \mathrm{mV}$

0.1 กA
Figure 2. Bridge mode experiments on a single identified cholinergic neuron. Top traces in $A, B$, and $D$ are hyperpolarizing current steps; lower traces reflect the voltage of the cell. $A$, Application of $50 \mu \mathrm{M}$ NA hyperpolarized the cell with a complete recovery after washout. $B$, NA hyperpolarization as in $A$, except in low- $\mathrm{Ca}^{2+} \mathrm{ACSF}$ solution, demonstrating that NA is acting directly on the cell. C:Left trace, Individual traces of a single voltage deflection in response to a hyperpolarizing current pulse prior to NA application (Control) superimposed on one obtained during NA. The smaller voltage deflection during NA demonstrates the increase in whole-cell conductance. Right trace. The same cell in a low-Ca ${ }^{2+}$ solution, showing the absence of the calcium spike seen in the left trace. $D$, Application of NA after pretreatment with $1 \mu \mathrm{M}$ idazoxan. Idazoxan completely blocked the hyperpolarization (as in $A$ and $B$ ), and demonstrated that NA also exerts a small depolarization through a non- $\alpha 2$ receptor. adrenergic hyperpolarization of cholinergic neurons is mediated by the inwardly rectifying potassium current, $I_{K G}$.

\section{Discussion}

The principle findings of this study are (1) NA powerfully and directly inhibits identified LDT cholinergic neurons, (2) NA exerts its hyperpolarizing effect through an $\alpha 2$-adrenergic receptor, and (3) the noradrenergic hyperpolarization is the result of activation of the inwardly rectifying potassium current, $I_{\mathrm{K} \mathrm{T}_{\mathrm{T}}}$.

\section{Identification of cells studied with whole-cell patch clamp}

The present report, in addition to two recent studies using the whole-cell patch-clamp technique (Kamondi et al., 1992; Luebke et al., 1992), is a benchmark for being among the first to "patch and match" (Bloom, 1992). That is, identification of the neurotransmitter phenotype of a cell studied with the whole-cell patch-clamp technique is important for deriving conclusions about the significance of the results. We found that identified
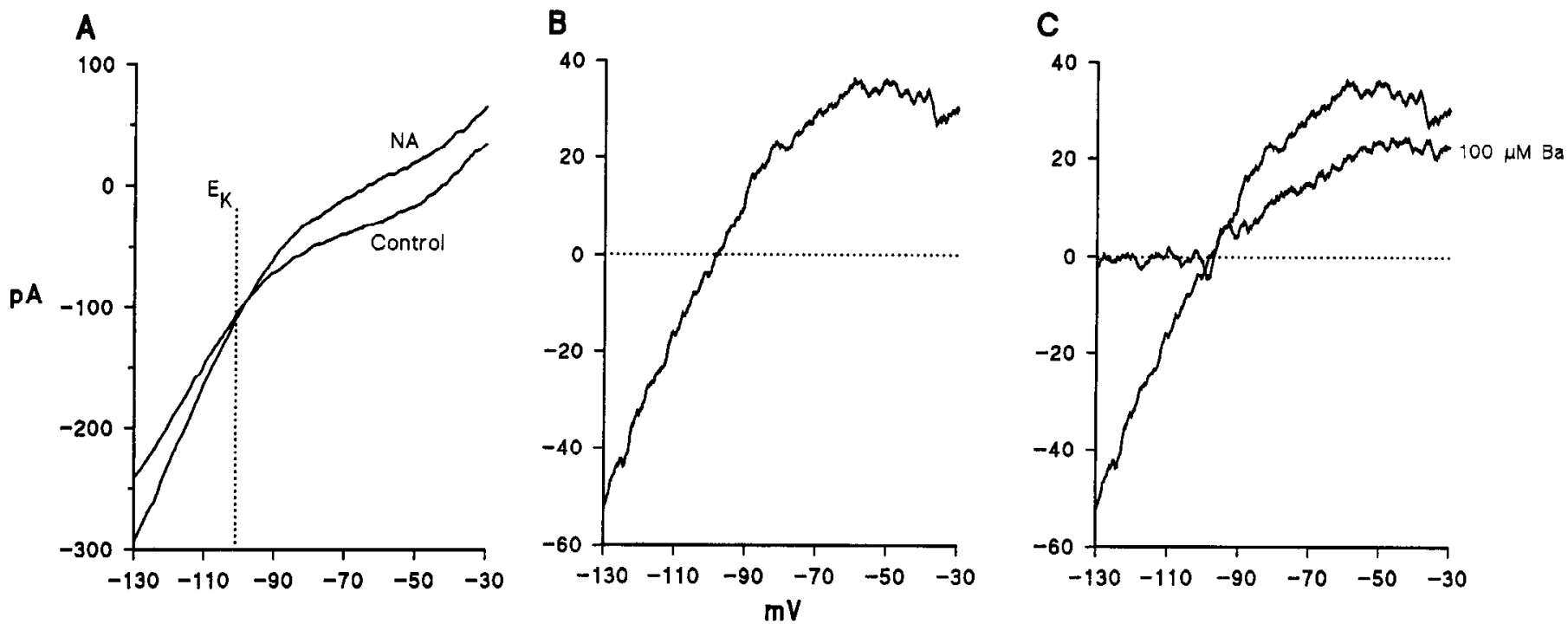

Figure 3. I- $V$ curves obtained from voltage-clamp experiments on an identified cholinergic neuron. $A$, Whole-cell currents obtained from control and during NA application approximate the potassium equilibrium potential $\left(E_{\mathrm{K}}\right)$, indicating the activation of a $\mathrm{K}^{+}$channel by NA. $B$, The $\mathrm{NA}^{-}$ evoked current (obtained by subtracting the control curve from the NA curve in $A$ ) shows inward rectification. $C$, The same curve as in $B$ superimposed on one obtained in a similar manner, except in a solution containing $100 \mu \mathrm{M} \mathrm{Ba}{ }^{2+}$. Barium completely blocked inward rectification as well as reduced the outward current. These results suggest that the NA hyperpolarization is due to the activation of the inwardly rectifying potassium current, $I_{\mathrm{KG}}$. 
cholinergic neurons had a homogeneous (and unambiguous) response to NA ( $92 \%$ hyperpolarized) whereas the noncholinergic cells, of which the phenotype is unknown, exhibited mixed responses to NA. Without histochemical identification of the cholinergic cells, we would have found that NA hyperpolarized only about half of LDT neurons, and to conclude that NA was inhibiting cholinergic neurons would have been only speculative. As it is, noradrenergic inhibition of cholinergic neurons is unequivocal.

\section{The $\alpha 2$-adrenergic receptor}

That the noradrenergic hyperpolarization of LDT cholinergic neurons is mediated by the $\alpha 2$-adrenergic receptor is supported by (1) blockade of the effect of NA by the $\alpha 2$-adrenergic antagonist idazoxan, (2) hyperpolarization induced by the $\alpha 2$-adrenergic agonist UK-14,304, and (3) the observation that the $\alpha 1$ and $\beta$-agonists phenylephrine and isoproterenol, respectively, failed to induce any effect.

Although a weak partial $\alpha 2$-adrenergic agonist (Medgett et al., 1978), clonidine is remarkably effective in mimicking noradrenergic inhibition in several different regions in the nervous system, including the LC (Cedarbaum and Aghajanian, 1977; Reiner, 1985; Williams et al., 1985), the rat sympathetic ganglion (Brown and Caufield, 1979), substantia gelatinosa (North and Yoshimura, 1984), and dorsal motor nucleus of the vagus (Fukuda et al., 1987). A notable exception is the submucous plexus of the guinea pig ileum. In these neurons, clonidine competitively antagonized the hyperpolarizing action of NA (Surprenant and North, 1988). Surprisingly, in LDT cholinergic neurons, clonidine was ineffective as either agonist or antagonist. These data suggest that LDT neurons may express a novel $\alpha 2-$ adrenergic receptor with a low affinity for clonidine. Support for this hypothesis derives from the recent cloning of three molecular species of $\alpha 2$-adrenergic receptor, although the pharmacological properties of these receptors are not yet known (Bylund, 1992). An alternative hypothesis is that dialysis of the cell interior using whole-cell patch-clamp recordings may modify the affinity of the receptor for clonidine. However, we found clonidine to hyperpolarize noradrenergic LC neurons powerfully using the whole-cell patch-clamp technique (J. A. Williams and P. B. Reiner, unpublished observations), making it unlikely that the inability of LDT cholinergic neurons to respond to clonidine is due to experimental error. Further investigation is needed to determine precisely which $\alpha 2$-adrenergic receptor subtype is involved in the noradrenergic inhibition of LDT cholinergic neurons.

Although we have deduced the mechanism of the NA hyperpolarization, the mechanism of the depolarizing effect of NA observed during $\alpha 2$-blockade by idazoxan has yet to be delineated. Clearly, a second receptor that is coupled to a different ion channel is involved. Consistent with these findings, in a minority of cells the reversal potential of the NA-induced hyperpolarization was somewhat depolarized to $E_{\mathrm{K}}(-80$ to -70$)$. Whether this phenomenon is due to a voltage-clamp error or to the activation of a separate set of ion channels is unclear. In any case, the hyperpolarization is unambiguously the predominant effect of NA and thus we did not investigate the "hidden" effect any further.

\section{Implications for behavioral state control}

For many years, several lines of evidence have implicated an inhibitory role of noradrenergic neurons of the LC in REM sleep generation (reviewed in Steriade and McCarley, 1990). Karczmar et al. (1970) demonstrated that absence of aminergic transmission was required to induce REM sleep systemically with AChE inhibitors. Based upon these and other findings, many have hypothesized noradrenergic inhibition of brainstem cholinergic mechanisms (McCarley and Hobson, 1975; Sakai, 1988; Steriade and McCarley, 1990). Recent data have provided a plausible anatomical substrate for such effects: catecholaminergic fibers synapse onto LDT cholinergic neurons (Kubota et al., 1992), and LC neurons project to the LDT (Semba and Fibiger, 1992). The present data extend such findings into the functional realm by directly confirming the hypothesis that NA inhibits mesopontine cholinergic neurons. Taken together with previous work these results allow us to define selected aspects of the cellular control of behavioral state with certainty.

Based upon electrophysiological data showing that the LC and DR are most active during wake and silent during RFM sleep (Hobson et al., 1975; McGinty and Harper, 1976; Trulson and Jacobs, 1979; Aston-Jones and Bloom, 1981; Reiner, 1985), and upon recent reports that both NA and 5-HT hyperpolarize LDT cholinergic neurons (Luebke et al., 1992; present report), we hypothesize that during wake cholinergic neurons are under considerable inhibitory tone. At the transition to REM sleep when aminergic neurons fall silent (Hobson et al., 1975; McGinty and Harper, 1976; Trulson and Jacobs, 1979; Aston-Jones and Bloom, 1981; Reiner, 1985), cholinergic neurons are disinhibited. Now capable of robust activity, they release $\mathrm{ACh}$ in the MPRF and trigger the state of REM sleep.

In the past few years, considerable strides have been made in understanding the neuronal control of behavioral states. Key to the enterprise have been critical tests of cxplicit and implicit models based upon molecular circuit analysis. The present experiments firmly establish the cellular basis of noradrenergiccholinergic interaction in the brainstem, with attendant implications for behavioral state control.

\section{References}

Amatruda T, Black D, McKenna T, McCarley RW, Hobson JA (1975) Sleep cycle control and cholinergic mechanisms: differential effects of carbachol injections at pontine brain stem sites. Brain Res 98:501515.

Aston-Jones G, Bloom FE (1981) Activity of norepinephrine-containing locus coeruleus neurons in behaving rats anticipates fluctuations in the sleep-waking cycle. J Neurosci 1:876-886.

Baxter BL (1969) Induction of both emotional behavior and a novel form of REM sleep by chemical stimulation applied to cat mesencephalon. Exp Neurol 23:220-229.

Bloom FE (1992) Training neuroscientists for the 21 st century. Trends Neurosci 15:383-386.

Brown DA, Caufield MP (1979) Hyperpolarizing ' $\alpha{ }_{2}$ '-adrenoceptors in rat sympathetic ganglia. $\mathrm{Br} \mathrm{J}$ Pharmacol 65:435-445.

Bylund DB (1992) Subtypes of $\alpha_{1}$-and $\alpha_{2}$-adrenergic receptors. FASEB J 6:832-839.

Cambridge D (1981) UK 14,304, a potent and selective alpha2-agonist for the characterization of alpha-adrenoceptor subtypes. Eur J Pharmacol 72:413-415.

Cedarbaum JM, Aghajanian GK (1977) Catecholamine receptors on locus coeruleus neurons: pharmacological characterization. Eur J Pharmacol 44:375-385.

El Mansari M, Sakai K, Jouvet M (1989) Unitary characteristics of presumptive cholinergic tegmental neurons during the sleep-waking cycle in freely moving cats. Exp Brain Res 76:519-529.

Fukuda A, Minami T, Nabekura J, Oomura Y (1987) The effects of noradrenaline on neurones in the rat dorsal motor nucleus of the vagus in vitro. J Physiol (Lond) 393:213-231.

Hallanger A, Wainer BH (1988) Ascending projections from the pe- 
dunculopontine tegmental nucleus and the adjacent mesopontine tegmentum in the rat. J Comp Neurol 274:483-515.

Hille B (1992) G protein-coupled mechanisms and nervous signalling. Neuron 9:187-195

Hobson JA, McCarley RW, Wyzinski PW (1975) Sleep cycle oscillation: reciprocal discharge by two brainstem neuronal groups. Science 189:55-58.

Hobson JA, Lydic R, Baghdoyan HA (1986) Evolving concepts of sleep cycle generation: from brain centers to neuronal populations. Behav Brain Sci 9:371-448.

Jones BE (1990) Immunohistochemical study of choline acetyltransferase-immunoreactive processes and cells innervating the pontomedullary reticular formation in the rat. J Comp Neurol 295:485514.

Jones BE, Beaudet A (1987) Distribution of acetylcholine and catecholamine neurons in the cat brain stem: a choline acetyltransferase and tyrosine hydroxylase immunohistochemical study. J Comp Neurol 261:15-32.

Kamondi A, Williams JA, Hutcheon B, Reiner PB (1992) Membrane properties of mesopontine cholinergic neurons studied with the wholecell patch-clamp technique: implications for behavioral statc control. J Neurophysiol 68:1359-1371.

Karczmar AG, Longo VG, Scotti de Carolis A (1970) A pharmacological model of paradoxical sleep: the role of cholinergic and monoamine systems. Physiol Behav 5:175-182.

Kubota Y, Leung E, Vincent SR (1992) Ultrastructure of cholinergic neurons in the laterodorsal tegmental nucleus of the rat: interaction with catecholamine fibers. Brain Res Bull 29:479-491.

Luebke JI, Greene RW, Semba K, Kamondi A, McCarley RW, Reiner PB (1992) Serotonin hyperpolarizes cholinergic low-threshold burst neurons in the rat laterodorsal tegmental nucleus in vitro. Proc Natl Acad Sci USA 89:743-747.

McCarley RW, Hobson JA (1975) Neuronal excitability modulation over the sleep cycle: a structural and mathematical model. Science 189:58-60.

McGinty DJ, Harper RM (1972) 5-HT containing neurons: unit activity during sleep. Sleep Res 1:27.

McGinty DJ, Harper RM (1976) Dorsal raphe neurons: depression of firing during sleep in cats. Brain Res 101:569-575.

Medgett IC, McCulloch MW, Rand MJ (1978) Partial agonist action of clonidine on prejunctional and postjunctional $\alpha$-adrenoceptors. Naunyn Schmiedebergs Arch Pharmacol 304:21 5-221.

Mitani A, Ito K, Hallanger AE, Wainer BH, Kataoka K, McCarley RW (1988) Cholinergic projections from the laterodorsal and pedunculopontine tegmental nuclei to the pontine gigantocellular tegmental field in the cat. Brain Res 451:397-402.

Mitler MM, Dement WC (1974) Cataplectic-like behavior in cats after microinjections of carbachol in pontine reticular formation. Brain Res 68:335-343.

North RA, Yoshimura M (1984) The actions of noradrenaline on neurones of the rat substantia gelatinosa in vitro. J Physiol (Lond) 349:43-55.

Quattrochi JJ, Mamelak AN, Madison RD, Macklis JD, Hobson JA (1989) Mapping neuronal inputs to REM sleep induction sites with carbachol-fluorescent microspheres. Science 245:984-986.

Reiner PB (1985) Clonidine inhibits central noradrenergic neurons in unanesthetized cats. Eur J Pharmacol 115:249-257.
Sakai K (1988) Executive mechanisms of paradoxical sleep. Arch Ital Biol 126:239-257.

Satoh K, Fibiger HC (1986) Cholinergic neurons of the laterodorsal tegmental nucleus: efferent and afferent connections. I Comp Neurol 253:277-302.

Semba K, Fibiger HC (1992) Afferent connections of the laterodorsal and the pedunculopontine tegmental nuclei in the rat: a retro- and antero-grade transport and immunohistochemical study. J Comp Neurol 323:387-410.

Semba K, Reiner PB, Fibiger HC (1990) Single cholinergic mesopontine tegmental neurons project to both the pontine reticular formation and the thalamus in the rat. Neuroscience 38:643-654.

Shiromani PJ, Armstrong DM, Gillin JC (1988) Cholinergic neurons from the dorsolateral pons project to the medial pons: a WGA-HRP and choline acetyltransferase immunohistochemical study. Neurosci Lett 95:19-23.

Siegel JM, McGinty DJ (1977) Pontine reticular formation neurons: relationship of discharge to motor activity. Science 196:678-680.

Sofroniew MV, Priestly JV, Consolazione A, Eckenstein F, Cuello AC (1985) Cholinergic projections from the midbrain and pons to the thalamus in the rat, identified by combined retrograde tracing and choline acetyltransferase immunohistochemistry. Brain Res 329:213223.

Steriade M, McCarley RW (1990) Brainstem control of wakefulness and sleep. New York: Plenum.

Steriade M, Pare D, Parent A, Smith Y (1988) Projections of cholinergic and noncholinergic neurons of the brain stem core to relay and associational thalamic nuclei in the cat and macaque monkey. Neuroscience 25:47-67.

Steriade M, Datta S, Pare D, Oakson G, Curro Dossi R (1990) Neuronal activities in brain-stem cholinergic nuclei related to tonic activation processes in thalamocortical systems. J Neurosci 10:25412559.

Surprenant A, North RA (1988) Mechanism of synaptic inhibition by noradrenaline acting at $\alpha_{2}$-adrenoceptors. Proc R Soc Lond [Biol] 234 85-114.

Trulson ME, Jacobs BL (1979) Raphe unit activity in freely moving cats: correlation with level of behavioral arousal. Brain Res 163:135150.

Vertes RP (1977) Selective firing of rat pontine gigantocellular neurons during movement and REM sleep. Brain Res 128:146-152.

Vincent SR, Reiner PB (1987) The immunohistochemical localization of choline acetyltransferase in the cat brain. Brain Res Bull 18:371415 .

Vincent SR, Satoh K, Armstrong DM, Fibiger HC (1983) NADPHdiaphorase: a selective histochemical marker for the cholinergic neurons of the pontine reticular formation. Neurosci Lett 43:31-36.

Williams JT, Henderson G, North RA (1985) Characterization of $\alpha_{2}$ adrenoceptors which increase potassium conductance in rat locus coeruleus neurons. Neuroscience 14:95-102.

Woolf NJ, Butcher LL (1986) Cholinergic systems in the rat brain. III. Projections from the pontomesencephalic tegmentum to the thalamus, tectum, basal ganglia and basal forebrain. Brain Res Bull 16: 603-637. 